Citation: M. Ziaee, M. Taseidifar, R.M. Pashley, B.W. Ninham (2020) Efficient Dewatering of Slimes and Sludges with a Bubble Column Evaporator. Substantia 4(2) Suppl.: 89-94. doi: 10.36253/ Substantia-841

Copyright: (c) 2020 M. Ziaee, M. Taseidifar, R.M. Pashley, B.W. Ninham. This is an open access, peer-reviewed article published by Firenze University Press (http://www.fupress.com/substantia) and distributed under the terms of the Creative Commons Attribution License, which permits unrestricted use, distribution, and reproduction in any medium, provided the original author and source are credited.

Data Availability Statement: All relevant data are within the paper and its Supporting Information files.

Competing Interests: The Author(s) declare(s) no conflict of interest.

\section{Efficient Dewatering of Slimes and Sludges with a Bubble Column Evaporator}

\author{
Mohammad Ziaee ${ }^{1}$, Mojtaba Taseidifar ${ }^{1}$, Richard M. Pashley ${ }^{1, *}$, Barry \\ W. NINHAM ${ }^{2}$ \\ ${ }^{1}$ School of Science, UNSW Canberra, Northcott Drive, Canberra, Australia \\ ${ }^{2}$ Department of Applied Mathematics, Research School of Physical Sciences and Engi- \\ neering, Australian National University, Canberra, Australia \\ ${ }^{*}$ Corresponding author: r.pashley@adfa.edu.au
}

\begin{abstract}
The recalcitrant nightmare of de-watering slime/sludge is a major issue, for both industry and the environment. A simple process is developed that solves the problem. It uses a bubble column evaporator (BCE) with heated dry air. The model slime to illustrate the de-watering process was a concentrated dispersion of spherical 5 micron silica particles in pure water. Typical slime samples were de-watered in the range $20-35 \%$ colloid/water $(\mathrm{w} / \mathrm{w})$ using dry inlet gases pre-heated to temperatures of $150^{\circ} \mathrm{C}$ and $250{ }^{\circ} \mathrm{C}$. The BCE process was run at sub-boiling temperatures, with the column solution in the range, 43 and $74{ }^{\circ} \mathrm{C}$, with those two inlet temperatures operating for de-watering the slime. A significant bonus is that the pure water vapour produced can be condensed and used as a source of high-quality water for reuse. The BCE process offers simplicity, resilience to slime feed quality, and a pure water biproduct. It also offers a continuous and controlled low-maintenance process. These are clear advantages in de-watering a wide variety of industrial slimes and sludges. In addition, the process involves the passage of a continuous flow of hot dry gases. This causes the dispersion to remain sufficiently fluid to allow easy transportation. However, once the hot gas flow ceased, the dispersion immediately solidified. The success of the bubble column process for dewatering and validation of the mechanism is even more enhanced if helium is used instead of air. It appears that hot helium atoms can disrupt water hydrogen-bonding in the liquid surrounding the hot bubbles and this enhances water vapour collection efficiency. The bubble method appears to offer more than significant advantages over other methods, such as hydrocyclone methods, which are often used to de-water mining wastes.
\end{abstract}

Keywords: slime and sludge de-watering, bubble column evaporator, silica spheres, helium gas.

\section{INTRODUCTION - SLIME AND SLUDGE DE-WATERING}

The words sludge or slime are used to mean a high water-content colloidal dispersion that stubbornly resists de-watering. De-watering is a process in which water is separated from the solids, to thicken up the waste for disposal or end-user purposes. This is a problem that poses major eco- 
nomic, environmental and safety challenges for a range of sludge types in industries like clay production, phosphate mining, diamond mining, sewage sludges, sand washing, and sludges from paper mills, gold mining, and different metallic ores. As an example, phosphate mining produces clay tailing slurries or sludges which are usually less than $10 \%$ solid content. This must be dewatered to a value of at least $40 \%$ by an economically acceptable process. Often the solid content has an average particle size equal to or less than 50 microns. This is generally characteristic of suspensions of siliceous and clay solids, and for other minerals, depending on the industrial process. ${ }^{1,2}$ Different techniques to dewater sludges are employed in different industries. They include coagulation, flocculation, grinding, heating, applying high voltages and using hydrocyclones. However, each of these techniques has its own drawbacks and they often fail to provide desirable solid content levels. For instance, flocculation and coagulation methods need considerable amounts of chemical agents which might cause environmental, economic and safety concerns. ${ }^{2,3}$

Conventional methods, for example ponding, also suffer from disadvantages. It is time consuming and requires large acreages of land to effectively de-water large volumes of slurries. This also increases land maintenance and remediation costs, also causes environmental and health issues. ${ }^{2}$ Hydrocyclones are frequently used in different industries for de-watering of solid-liquid suspensions. Generally, large hydrocyclones are used for separation of particles (larger than $25 \mu \mathrm{m}$ ) from slimes, while smaller hydrocyclones with diameters less than $10 \mathrm{~mm}$ are usually used to separate fine particles smaller than $10 \mu \mathrm{m}$.

The controllability and efficiency of the hydrocyclone method are limited and this method needs to be augmented by further processes like centrifugation to optimise dewatering. ${ }^{4}$ Hydrocyclones, in general, are comprised of an inlet, a main body and two outlets. In order to increase the recovery of solids, the feed pressure needs to be increased. Other conditions such as relationship between cutsize, bypass and water recovery determine the performance. Thus, depending on the waste type, they need to be optimised in order to obtain maximum efficiency in de-watering. ${ }^{5,6}$ Also, for further improvement of the hydrocyclone process, a centrifuge can also be incorporated. This uses centrifugal forces made by spinning a bowl or basket to separate the sludge solids from the liquid. ${ }^{7}$

In this work a novel method of de-watering slime using a bubble column evaporator (BCE) is developed and evaluated. This can be used for many different sludge thickening applications. The BCE exploits the

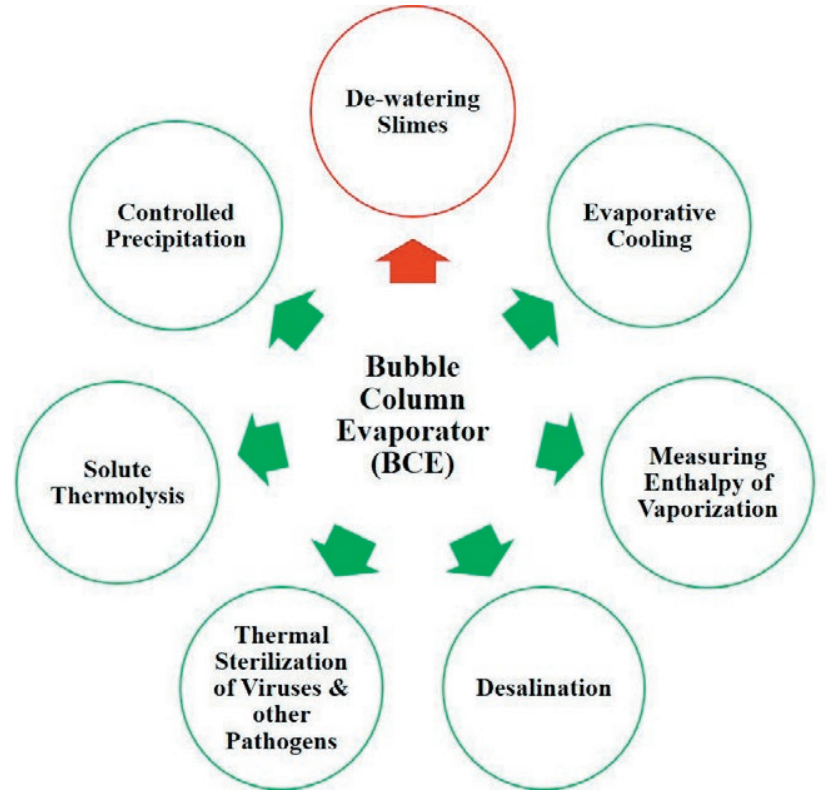

Figure 1. Different applications for the BCE process.

high interfacial area between gas bubbles and water and acts as a natural semi-permeable membrane. This process uses hot bubbles to allow water vapour to escape but not the solid particles. So far, a wide range of useful applications of the BCE process have been developed by our research group. The list includes: a new method for the precise measurement of enthalpies of vaporisation $\left(\Delta H_{\text {vap }}\right)$ of concentrated salt solutions; ${ }^{8,9}$ evaporative cooling; ${ }^{10}$ a new method for thermal desalination ${ }^{11-13}$ a novel method for sub-boiling thermal sterilization; ${ }^{9}, 14-18$ a novel method for the low-temperature thermal decomposition of some solutes in aqueous solution; ${ }^{19}$ and a new approach to aqueous solute precipitation in a controlled manner. ${ }^{20}$ In addition, a bubble column condenser has also been designed for the production of high- quality water as condensate. ${ }^{21-23}$ Figure 1 depicts the various applications of the BCE technique we have developed. The green arrows refer to the previous applications developed by the BCE method, while the red arrow refer to the latest application of this method.

\section{MATERIALS AND METHODS}

For each experiment $50 \mathrm{~g}$ of $5 \mu \mathrm{m}$ spherical silica powder supplied by US Research Nanomaterials Company was used. Milli-Q water was added to pure $50 \mathrm{~g}$ of silica powder to reach $250 \mathrm{~g}$ of water-silica mixture. Then, the mixtures were stirred to produce uniform dispersions. The measured turbidity of silica mixtures $(20 \%$ 
weight), was about 40,000 NTU measured by $\mathrm{HACH}$ 2100AN Turbidimeter. The concentration of solid particles (slime thickness) in the mixtures were calculated using the following formula:

solid concentration $\%=\frac{\text { weight of dry solid }}{\text { total weight of mixture }} \times 100$

The BCE process is illustrated schematically in Figure 2. In this work, four experiments were undertaken for de-watering the prepared slime samples using two different gases (dry air, helium) at two different outlet gas temperatures $\left(150^{\circ} \mathrm{C}, 250^{\circ} \mathrm{C}\right)$.

In each experiment, $250 \mathrm{~mL}$ of the prepared slime sample was poured into a $120 \mathrm{~mm}$ diameter open-top glass column (Büchner type, Pyrex ${ }^{\oplus}$ Borosilicate, VWR) with a sinter porosity of number 2 . The outlet gas temperature was varied using a Tempco air heater (300W) with a thermocouple temperature monitor and an AC Variac electrical supply. A TENMARS thermometer (TM-84N, Taiwan) with the accuracy of $\pm 1.5{ }^{\circ} \mathrm{C}$ was applied on the surface of the sinter to measure the temperature of hot gas introduced to the empty column.

The air gas was produced from an air pump (Hiblow HP40, Philippines) and a BOC gas flow meter was used to measure flow rates. The temperature of the column solution was also continuously monitored using a thermocouple positioned at the centre of the aqueous mixtures. Due to our requirement of a slime gas temperature up to $250{ }^{\circ} \mathrm{C}$, the temperature of the gas heater might reach above $700{ }^{\circ} \mathrm{C}$. That necessitates the use of a steel heater and brass connectors for the downstream, and the use of Rockwool as an insulating material.

The effectiveness of the BCE process was quantified experimentally based on the weight loss of the slime using the following equation:

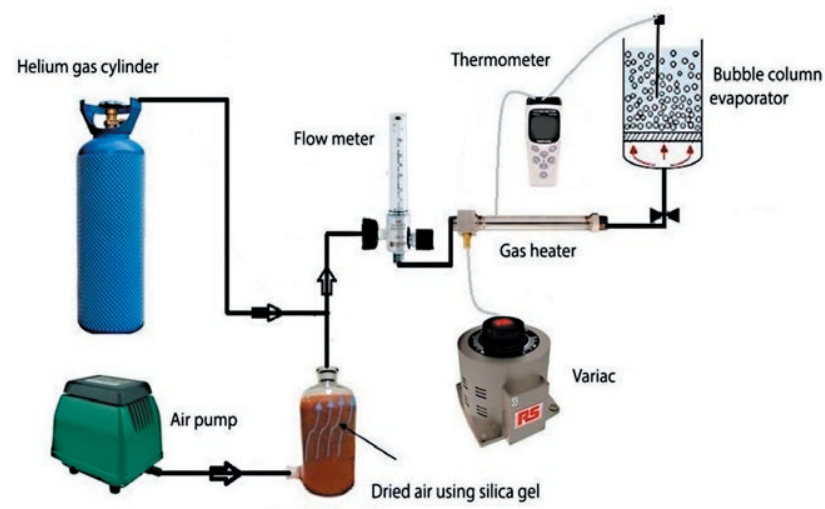

Figure 2. Schematic diagram of BCE system for slimes de-watering. water loss $\%=\frac{(W 1-W 2)}{(W 1-W d)} \times 100$

where $\mathrm{W}_{1}, \mathrm{~W}_{2}$, and $\mathrm{W}_{\mathrm{d}}$ are the initial weight of slime, final weight of slime, and the weight of dry solid compounds, respectively

\section{RESULTS AND DISCUSSION}

\subsection{Results for Air}

In the first experiment, $250 \mathrm{~g}$ of a silica-water mixture with a concentration of $20 \%$ was poured to the column using hot dry air at a temperature of $150{ }^{\circ} \mathrm{C}$. After 45 minutes using hot air with a flow rate of $34(\mathrm{~L} / \mathrm{min})$ for production of hot bubbles in the aqueous mixture, the residual mixture was weighed and the new solid concentration (slime thickness) was calculated using equation (1). The results are presented in Table 1. It shows that the final solid concentration (slime thickness) is $30.5 \%$. Also, the density of the dispersion was increased in this process from $1.05 \mathrm{~g} / \mathrm{mL}$ to $1.16 \mathrm{~g} / \mathrm{mL}$ and the operating temperature of the $\mathrm{BCE}$ slime remained at about $48-49^{\circ} \mathrm{C}$.

In the second experiment applying dry air at the temperature of $250{ }^{\circ} \mathrm{C}$ with a flow rate of $34 \mathrm{~L} / \mathrm{min}$ over 45 minutes, the silica concentration increased from 20 to $34.7 \%$. The temperature of the slime mixture remained in the range of $65-66{ }^{\circ} \mathrm{C}$. The density increased from an initial value of 1.05 to $1.25 \mathrm{~g} / \mathrm{mL}$. An example of the bubbling process is shown in the photograph in Figure 3.

\subsection{Results for Helium}

When helium gas was used for producing bubbles, the helium flow rates were measured using two methods: by weighing the helium cylinder and from calculations based on the helium cylinder pressure differential. The first method gave a flow rate of about $13.9 \mathrm{~L} / \mathrm{min}$ and the calculations based on the helium cylinder pressure differential led to a flow rate of $10.4 \mathrm{~L} / \mathrm{min}$. Therefore, an average value of $12 \mathrm{~L} / \mathrm{min}$ was used for comparison with the $34 \mathrm{~L} / \mathrm{min}$ dry air flow. According to the previous studies, helium is a more effective gas in bubbling because of its natural production of smaller bubbles, even in pure water. ${ }^{13}$

In these experiments helium flowed into the BCE column containing $20 \%$ silica dispersion at an inlet temperature of $150{ }^{\circ} \mathrm{C}$, flow rate of $12 \mathrm{~L} / \mathrm{min}$. After $45 \mathrm{~min}$ with the column solution equilibrating at about $41{ }^{\circ} \mathrm{C}$, the silica concentration was increased to $28 \%$ and the 


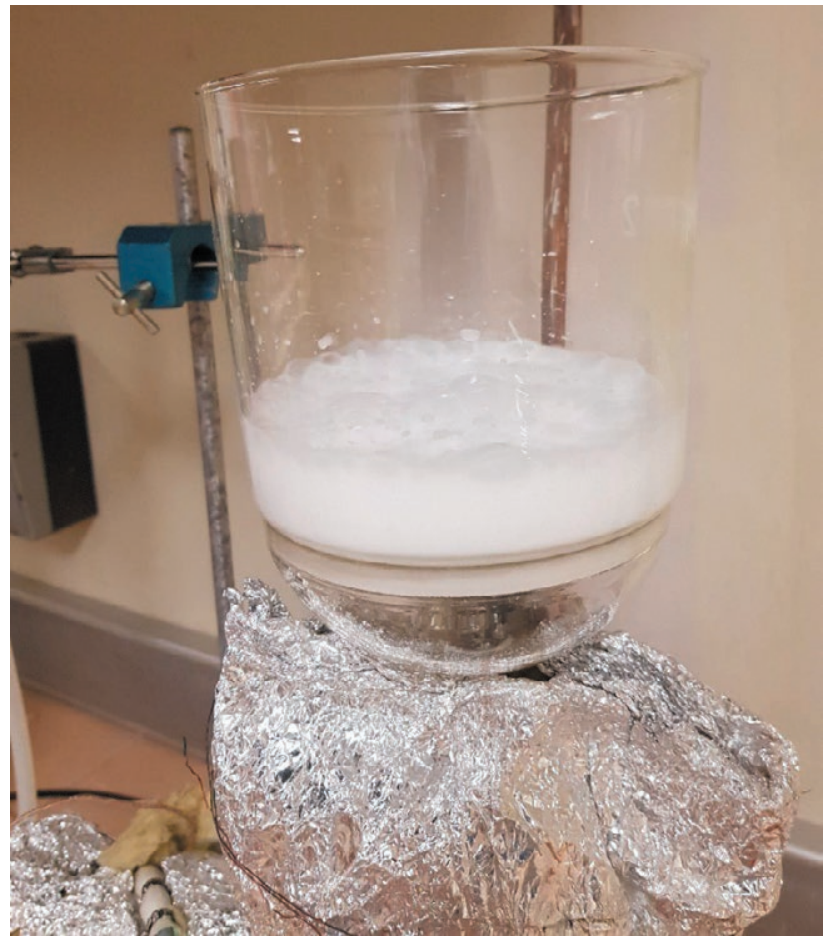

Figure 3. Photograph of the BCE process applied to $20 \%$ silica slimes using hot air.

solution density increased from $1.05 \mathrm{~g} / \mathrm{mL}$ to $1.19 \mathrm{~g} / \mathrm{mL}$. When the helium inlet gas temperature was increased to $250{ }^{\circ} \mathrm{C}$ at $12 \mathrm{~L} / \mathrm{min}$, after $45 \mathrm{~min}$ with the column solution equilibrating at about $63^{\circ} \mathrm{C}$, the silica concentration (slime thickness) was increased to $32.5 \%$ and the solution density increased from $1.05 \mathrm{~g} / \mathrm{mL}$ to $1.23 \mathrm{~g} / \mathrm{mL}$. Table 1 summarises the de-watering results of $20 \%$ silica slimes using BCE process with air and helium gases.

At these high silica content levels, the dispersion remained sufficiently fluid for reasonable transport but on stopping the hot inlet gas flow the dispersion immediately solidified.

The values reported in Table 1 are the mean values calculated based on the data obtained after three runs for each single experiment. Besides undertaking experiments using silica-water slime, four experiments have been carried out using both air and helium (at $150{ }^{\circ} \mathrm{C}$ and $250{ }^{\circ} \mathrm{C}$ ) with an industrial slime which had a similar compound composition. The results achieved were very close to the results obtained for de-watering the model silica slime.

Figure 4 shows a Scanning Electron Microscopy (SEM) image of the precipitated silica particles used in this study. This shows that they are of spherical appearance and very fine.

Fine particles (e.g., silica spheres) can stabilise foams even in the absence of surfactants or polymers. ${ }^{25}$ Aque-
Table 1. De-watering of initial 20\% silica slime (density of $1.05 \mathrm{~g} /$ $\mathrm{mL}$ ) using BCE process with different gases (air and helium).

\begin{tabular}{cccccc}
\hline & $\begin{array}{c}\text { Gas Flow } \\
\text { Rate } \\
(\mathrm{L} / \mathrm{min})\end{array}$ & $\begin{array}{c}\text { Gas Tem- } \\
\text { perature } \\
\left({ }^{\circ} \mathrm{C}\right)\end{array}$ & $\begin{array}{c}\text { Slime Tem- } \\
\text { perature } \\
\left({ }^{\circ} \mathrm{C}\right)\end{array}$ & $\begin{array}{c}\text { Slime } \\
\text { Thickness } \\
(\%)\end{array}$ & $\begin{array}{c}\text { Slime } \\
\text { Density } \\
(\mathrm{g} / \mathrm{mL})\end{array}$ \\
\hline BCE & 34 & 150 & $48-49$ & 30.5 & 1.16 \\
with air & 34 & 250 & $65-66$ & 34.7 & 1.25 \\
BCE & 12 & 150 & 41 & 28.0 & 1.19 \\
with He & 12 & 250 & 63 & 32.5 & 1.23 \\
\hline
\end{tabular}

ous foams stabilised solely by particles, but these are usually partially hydrophobic and so have an amphiphilic nature. ${ }^{25}$ The studies reported here were based on the use of hydrophilic silica particles dispersed in pure water. These micron sized particles would generally act to destabilise foams via water film rupture and hence even with continuous air and helium gas flow no significant level of transient foaming was observed.

The relative water loss under different conditions is calculated based on equation (2) and summarised in Figure 5. Regarding the Figure, using helium gas is much more effective than dry air since this level of de-watering was achieved at about one third of the volumetric flow rate compared with air.

In order to compare the efficiency of using different gases for slime de-watering the following equation 3 was used:

$\frac{E 1}{E 2}=\frac{C p 2}{C p 1} \times \frac{F 2}{F 1} \times \frac{\text { water loss }(1)}{\text { water } \operatorname{loss}(2)}$

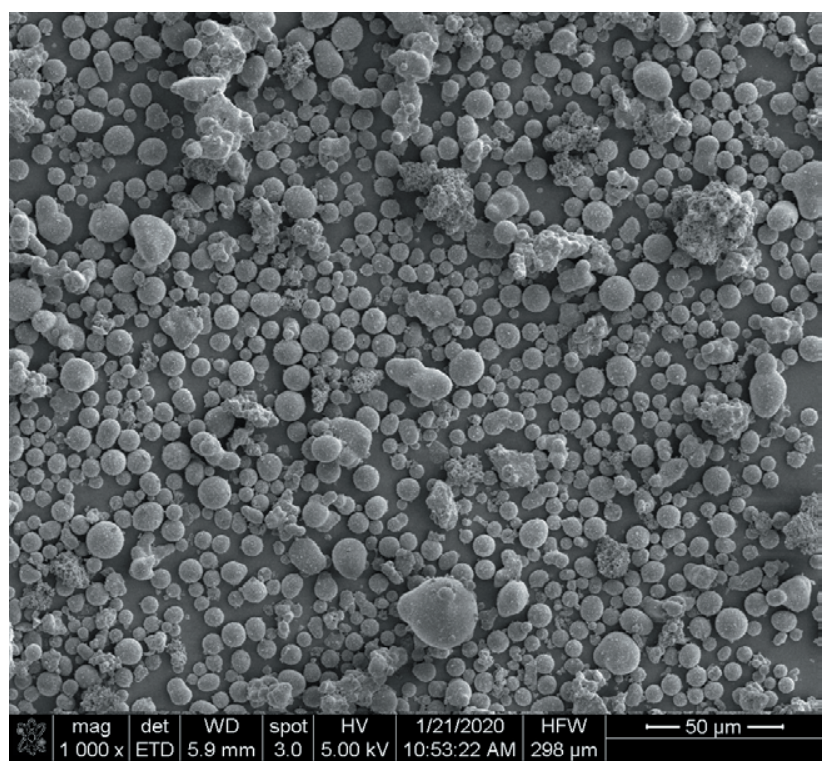

Figure 4. SEM of micro-silica spheres produced by precipitation. 


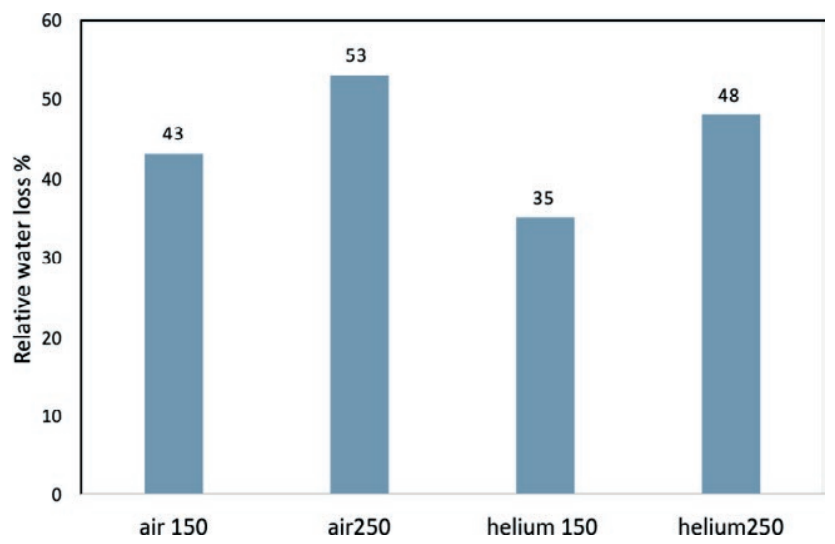

Figure 5. Comparison of the water loss \% using air vs helium at 150 ${ }^{\circ} \mathrm{C}$ and $250^{\circ} \mathrm{C}$. Note that the $\frac{\text { helium flow rate }}{\text { air flow rate }}=\frac{1}{3}$.

where $E, C_{p}, F$ are efficiency of gas carrier, heat capacity of gas at the constant pressure, and gas flow rate, respectively. Also, numbers refer to gas carrier 1 and 2. The water loss factor for each gas carrier can be calculated from equation (2) and the $\mathrm{C}_{\mathrm{p}}$ value for air and helium gases are 29.31 and $20.77\left(\mathrm{~J} \mathrm{~mole}^{-1} \mathrm{~K}^{-1}\right)$, respectively. The $\mathrm{E}_{\mathrm{Helium}} / \mathrm{E}_{\mathrm{Air}}$ ratio regarding operational temperatures at $150{ }^{\circ} \mathrm{C}$ and $250^{\circ} \mathrm{C}$, gas flow rates, and water loss are 3.25 and 3.62 respectively. This means that to reach an equal level of slime de-watering, helium almost needs less than $1 / 3$ of the energy which air needs.

\section{CONCLUSIONS}

The BCE system was found to be very effective for slime de-watering. This is major step forward. Its effectiveness was found to depend on the gas temperature. Heated dry air gas at $250{ }^{\circ} \mathrm{C}$ was found to be significantly more effective than applying hot dry air at $150{ }^{\circ} \mathrm{C}$ to concentrate the slime. It was found that helium gas is more effective than air. We conjecture that this might be due to the very small size of a helium atom with a diameter of $62 \mathrm{pm}$. Helium atoms can break the hydrogen bonding among water molecules adjacent to the gas-liquid interface and allow easier transfer of water molecules into the rising helium bubbles. (The length of hydrogen bonding among water molecules in the liquid phase is about $1.97 \AA$ ).

The BCE method using hot, dry carrier gases offers a promising technique to de-water a wide variety of slimes and slurries produced in different industries. It is simple and robust. This process might offer a novel competitive dewatering process and could be readily scaled up. It offers a robust process which can replace existing tech- niques such as flocculation, hydrocyclones, and ponding. The BCE technique applied to de-watering also has the very significant additional advantage of producing high quality water from condensation of the sub-boiling water vapour.

\section{REFERENCES}

1. N.C. Lockhart, Electro-osmotic dewatering of fine tailings from mineral processing, Int. J. Miner. Process., 1983, 10(2), 131-140.

2. T.J. Laros, Flocculating agent combinations for mineral slime filtration systems, 1990, Envirotech Corp, United States Patent, Patent No: 4,931,190.

3. P. Pirkonen, B. Ekberg, Chapter Nine - Ultrasonic, Prog. Filtr. Sep., 2015, 399-421.

4. S. Pasquier, J.J. Cilliers, Sub-micron particle dewatering using hydrocyclones, Chem. Eng. J., 2000, 80(1), 283-288.

5. J.J. Cilliers, L. Diaz-Anadon, F.S. Wee, Temperature, classification and dewatering in $10 \mathrm{~mm}$ hydrocyclones, Miner. Eng., 2004, 17(5), 591-597.

6. D. Vega-Garcia, P.R. Brito-Parada, J.J. Cilliers, Optimising small hydrocyclone design using 3D printing and CFD simulations, Chem. Eng. J., 2018, 350, 653-659.

7. G. Chen, P. Lock Yue, A.S. Mujumdar, sludge dewatering and drying, Drying Technol., 2002, 20(4-5), 883-916.

8. C. Fan, R.M. Pashley, Precise Method for Determining the Enthalpy of Vaporisation of Concentrated Salt Solutions Using a Bubble Column Evaporator. J. Sol. Chem., 2015. 44(1), 131-145.

9. C. Fan, M. Shahid, R.M. Pashley, Studies on bubble column evaporation in various salt solutions, J. Sol. Chem., 2014, 43(8), 1297-1312.

10. M. Francis, R.M. Pashley, Application of a Bubble Column for Evaporative Cooling and a Simple Procedure for Determining the Latent Heat of Vaporization of Aqueous Salt Solutions, J. Phys. Chem. B, 2009, 113(27), 9311-9315.

11. M.J. Francis, R.M. Pashley, Thermal desalination using a non-boiling bubble column. Desalination and Water Treat., 2009, 12(1-3), 155-161.

12. M. Shahid, R.M. Pashley, A study of the bubble column evaporator method for thermal desalination, Desalination, 2014, 351, 236-242.

13. M. Taseidifar, M. Shahid, R.M. Pashley, A study of the bubble column evaporator method for improved thermal desalination, Desalination, 2018, 432, 97-103.

14. X. Xue, R.M. Pashley, A study of low temperature inactivation of fecal coliforms in electrolyte solutions 
using hot air bubbles, Desalination and Water Treat., 2016, 57, 9444-9454.

15. M. Shahid, A study of the bubble column evaporator method for improved sterilization, J. Water Process. Eng., 2015, 8, 1-6.

16. A.G. Sanchis, M. Shahid, R.M. Pashley, Improved virus inactivation using a hot bubble column evaporator (HBCE), Colloids Surf. B: Biointerfaces, 2018, 165, 293-302.

17. A.G. Sanchis, R.M. Pashley, B. Ninham, Virus and bacteria inactivation by $\mathrm{CO}_{2}$ bubbles in solution, NPJ Clean Water, 2019, 2, 5.

18. M. Shahid, R.M. Pashley, M. Rahman, Use of a high density, low temperature, bubble column for thermally efficient water sterilisation, Desalination and Water Treat., 2014, 52, 4444-4452.

19. M. Shahid, X. Xue, C. Fan, B.W. Ninham, R.M. Pashley, Study of a novel method for the thermolysis of solutes in aqueous solution using a low temperature bubble column evaporator, J. Phys. Chem. B, 2015, 119 (25), 8072-8079.

20. C. Fan, R.M. Pashley, The controlled growth of calcium sulfate dihydrate (gypsum) in aqueous solution using the inhibition effect of a bubble column evaporator, Chem. Eng. Sci., 2016, 142, 23-31.

21. P.N. Govindan, G.P. Thiel, R.K. McGovern, J.H. Lienhard, M.H. Elsharqawy, Bubble-Column Vapor Mixture Condenser, 2013, United States Patents, Patent No: US 8.523,985 B2.

22. G.P. Narayan, J.H. Lienhard, Thermal Design of Humidification- Dehumidification Systems for Affordable Small-Scale Desalination, IDA J. Desalination Water Reuse, 2012. 4(3), 24-34.

23. M. Schmack, H. Goen, A. Martin, A Bubble Column Evaporator with Basic Flat-plate Condenser for Brackish and Seawater Desalination, Environ. Technol., 2015, 37(1), 74-85.

24. M. Shahid, C. Fan, R.M. Pashley, Insight into the bubble column evaporator and its applications, Int. Rev. Phys. Chem., 2016, 35(1), 143- 185.

25. A. Stocco, E. Rio, B. P. Binks, D. Langevin, Aqueous foams stabilized solely by particles, Soft Matter, 2011, 7(4), 1260-1267. 